\title{
Effect of Silver Particle-longkong Peel Extract Coating on Postharvest Decay and Browning in Longkong Fruit
}

\author{
Intira Lichanporn ${ }^{1 *}$, Chairat Techavuthiporn ${ }^{2}$ and Chalermchai Wongs-Aree ${ }^{3,4}$ \\ ${ }^{1}$ Division of Food Science and Technology, Faculty of Agricultural Technology, Rajamangala University of Technology \\ Thanyaburi, Phathum Thani, Thailand \\ ${ }^{2}$ Department of Agricultural Education, Faculty of Industrial Education and Technology, King Mongkut's Institute of Technology \\ Ladkrabang, Ladkrabang, Bangkok 10520, Thailand \\ ${ }^{3}$ Division of Postharvest Technology, School of Bioresources and Technology, King Mongkut's University of Technology Thonburi, \\ Bangkok, Thailand \\ ${ }^{4}$ Postharvest Technology Innovation Center, Ministry of Higher Education, Science, Research and Innovation, Bangkok 10400, \\ Thailand
}

\begin{abstract}
We aimed to assess the effect of longkong peel extract (LPE)-silver particle-alginate coating on the postharvest decay and browning of longkong fruit during storage at $13^{\circ} \mathrm{C}$ and $90-95 \%$ relative humidity (RH). Longkong was coated with $0,0.45$ or $0.90 \mathrm{mg} \cdot \mathrm{L}^{-1} \mathrm{LPE}$ in silver particle-alginate solution and then stored at $13^{\circ} \mathrm{C}$ and 90 95\% RH for nine days. In the mixture consisting of the longkong peel extract and silver solution, the silver particle size was modified to yield fine particles. Electron micrography showed the presence of silver particle sizes ranging in size from approximately $71-625 \mathrm{~nm}$. Fruit coated without LPE exhibited severe browning, weight loss and decay incidence during storage. Coating with 0.45 and $0.90 \mathrm{mg} \cdot \mathrm{L}^{-1} \mathrm{LPE}$ significantly inhibited the increase in fruit browning by mainly reducing peroxidase (POD) and polyphenol oxidase (PPO) activities. LPE coating effectively reduced the longkong weight loss and decay incidence. No fruit treatment showed a significant titratable acidity change or increased soluble solids at the end of storage. These results indicate that coating with LPE is a promising approach to inhibit decay and browning and to maintain the quality of longkong during low-temperature storage.
\end{abstract}

Key Words: coating, longkong peel extract, polyphenol oxidase, silver particles.

\section{Introduction}

Longkong (Aglaia dookkoo Griff.), a member of the Meliaceae family, has recently become an economically valuable fruit for Thailand in export markets. The fruit originates from southern Thailand, and major longkong cultivation now currently occurs in the eastern regions. Longkong is a non-climacteric tropical fruit, with a high fresh market value. However, the fruit rapidly loses postharvest quality due principally to peel (pericarp) browning and postharvest disease infection, resulting in price reduction. The fruit is susceptible to

Received; July 26, 2019. Accepted; December 10, 2019.

First Published Online in J-STAGE on February 8, 2020.

This work was supported by the Thailand Research Fund (TRF) and Rajamangala University of Technology Thanyaburi (RMUTT) during the two-year planning period (Contract No. TRG5780244).

* Corresponding author (E-mail: intira 1@rmutt.ac.th). decay caused by fungal and bacterial infections during storage (Venkatachalam, 2016). The most common types of fruit diseases include sooty mold (Meliola spp.) and fruit rot (Cylindrocladium spp.) (Suanphairoch et al., 2003). The biological browning process in plants has been reported to be mainly associated with the oxidizing action of PPO on polyphenols to produce quinones that are later responsible for polymerization of the developed colour (Chang, 2009; Constabel and Barbehenn, 2008; Queiroz et al., 2008). Although it is difficult to maintain the appearance of the fruit at room temperature without proper postharvest conditions, numerous methods can prevent oxidation, such as chemicals, controlled atmosphere environments and coating treatments. Fruit coatings have been extensively studied to extend the shelf life of many fresh fruits. In the present study, modified coating materials were used to maintain the postharvest quality of longkong. 
In addition to the prevention of weight loss and control of gaseous permeability, fruit coatings are generally used as antimicrobials to reduce or inhibit the growth of microorganisms. Edible coatings on foods can prevent moisture loss, water vapor transfer between components in a heterogeneous food system, ice formation in frozen foods, and gaseous permeability of gases such as oxygen and carbon dioxide (Baldwin, 2007; Cutter and Summer, 2002; Ustunol, 2009). Coatings are not only used to coat products from animals or processed foods (Coma, 2008; Ustunol, 2009) but also fruits, vegetables, and minimally processed or fresh-cut produce (RojasGraü et al., 2009). Alginate is a natural polysaccharide extracted from brown seaweed belonging to the family Phaeophyceae (Valero et al., 2013). The colloidal properties of alginate enable it to thicken and stabilize insoluble polymers in a reaction with multivalent metal cations such as calcium (Montero-Calderón et al., 2008). The application of an alginate coating on whole fruits has maintained the quality of guavas (Nair et al., 2018), enhanced the shelf life of mandarin (Chen et al., 2016) and okra (Gundewadi et al., 2018) and delayed weight and acidity loss, softening and colour changes in plum cultivars (Valero et al., 2013).

As for antimicrobial properties, additional elements are mixed with the coating materials. In addition to using natural preservatives, noble-metal nanomaterials such as silver nanoparticles have received positive attention because of their desirable physicochemical properties. Silver $\left(\mathrm{Ag}^{2+}\right)$, probably in different ionic forms, is extremely effective at damaging a vast range of microorganisms (Liau et al., 1997). Silver particles can be synthesized by various techniques, including physical, chemical, and biological methods (Nair and Laurencin, 2007; Sharma et al., 2009; Zhang et al., 2008). Over the past several years, there has been increasing interest in the applications of silver particles because of their antimicrobial activities (Choi et al., 2008), and they have been proposed as potential treatment agents (Rai et al., 2009). Kumar et al. (2015) developed a practical method to synthesize silver plates using peel rambutan extract that functioned as a stabilizing and reducing agent. The main constituents of rambutan peel are anthocyanins and other phenolic compounds; the inclusion of rambutan peel is beneficial for coating reactions because of its natural antioxidants. Consequently, rambutan peel extract can be used as an alternative agent to develop technology-based treatments (Lim, 2013; Kumar et al., 2015). In the present study, we were interested in using longkong peel as an agricultural waste for silver-particle production. Longkong peel contains many phytochemicals, such as antioxidants, phenolic compounds, scopoletin, rutin, and chlorogenic acid (Klungsupya et al., 2015), which can be finely incorporated with silver particles. Because size reduction of suitable material sources is the main purpose of making the particles (Meyers et al., 2006),
Kumar et al. (2015) demonstrated a reaction to produce silver particles by the addition of a natural plant extract. $\mathrm{Ag}^{2+}$ particles were highly induced to silver particles in both trigonal and hexagonal forms by mixing rambutan peel extract. It is therefore reasonable to suppose that longkong peel extract (LPE) biomolecules could play a role as a mild reducing agent for $\mathrm{Ag}^{2+}$ ions and as a capping agent for $\mathrm{Ag}$ particles. $\mathrm{Ag}^{2+}$ ions can interact with $\mathrm{O}-\mathrm{H}$ or $\mathrm{CHO}$ groups of the phytochemicals in the extract, subsequently leading to oxidation to the $-\mathrm{C}=\mathrm{O}$ and $-\mathrm{COOH}$ forms and size reduction of $\mathrm{Ag}^{2+}$ to silver particles (Cao et al., 2008; Kumar et al., 2015).

No information is available regarding the use of longkong peel extract to improve silver particles in alginate coating solutions or use of a modified coating to maintain the quality of fresh produce. The objective of this work was to assess the postharvest quality, decay, and browning of longkong fruit coated by longkong peel extract-silver particle-alginate during storage at $13^{\circ} \mathrm{C}$ and $90-95 \% \mathrm{RH}$.

\section{Materials and Methods}

\section{Fruit treatment}

In the preparation of longkong peel extract (LPE) powder, fresh longkong peels (120 fruits) were collected, washed, and boiled in distilled water (DW) for $30 \mathrm{~min}$ at $90^{\circ} \mathrm{C}$. The boiled peels $(100 \mathrm{~g})$ were crushed in $100 \mathrm{~mL}$ of DW. The peel homogenate was filtered through cheesecloth. The filtrate was then treated by using an equal volume of chilled acetone. The precipitate was collected after centrifuging the mixture at $1,000 \mathrm{rpm}$ for $5 \mathrm{~min}$. The pellet was air-dried to obtain an extract powder for further experimental use.

To prepare the alginate solution, $0.5 \%(\mathrm{w} / \mathrm{v})$ sodium alginate powder in DW was heated to $70^{\circ} \mathrm{C}$, and the solution was stirred until it became clear. Glycerol as a plasticizer at $1.5 \%(\mathrm{w} / \mathrm{v})$ was added to the alginate solution. $N$-Acetylcysteine $(1 \% \mathrm{w} / \mathrm{v})$ and calcium chloride $(2 \% \mathrm{w} / \mathrm{v})$ were added to the solution to make crosslinks of the carbohydrate polymers. Sunflower oil at $0.025 \%$ $(\mathrm{w} / \mathrm{v})$ was then added to emulsify the film-forming solution. The mixture was homogenized for $3 \mathrm{~min}$ at $12,500 \mathrm{rpm}$ using an Ultra Turrax T25 system (IKA Werke GMBH, Staufen, Germany) and then degassed under a vacuum. The formulation was chosen in accordance with the previous research of Rojas-Graü et al. (2006, 2007, 2008).

In the preparation of LPE-based silver particles, silver nitrate $\left(\mathrm{AgNO}_{3}\right)$ was first dissolved in DW at a concentration of $1.0 \mathrm{M}$ to produce an $\mathrm{AgNO}_{3}$ solution; LPE powder was dissolved in the $\mathrm{AgNO}_{3}$ solution $(0,1.0$ and $2.0 \mathrm{mg} \cdot \mathrm{L}^{-1}$ ) (Rojas-Graü et al., 2007). The LPE mixtures were incubated at $80^{\circ} \mathrm{C}$ in a water bath for $3 \mathrm{~min}$ at $\mathrm{pH} 3$ to induce the formation of smaller particles. Different concentrations of the mixtures were then incorporated into a $0.5 \%$ alginate coating solution. The final applied silver particles with longkong peel extract 
and alginate were used at concentrations of $0,0.45$ and $0.90 \mathrm{mg} \cdot \mathrm{L}^{-1} \mathrm{LPE}$ in a silver particle-alginate solution for coating. Treatment without $\mathrm{LPE}\left(0 \mathrm{mg} \cdot \mathrm{L}^{-1} \mathrm{LPE}\right)$ represented the control treatment.

Longkong fruit was collected from a commercial orchard located in 'Chanthaburi' province, eastern Thailand. Individual longkong fruit were submerged in $200 \mathrm{ppm}$ of sodium hypochloride solution for $15 \mathrm{~min}$ at room temperature and briefly air-dried. The treatments were as follows: (1) control treatment $\left(0 \mathrm{mg} \cdot \mathrm{L}^{-1} \mathrm{LPE}\right)$, (2) $0.45 \mathrm{mg} \cdot \mathrm{L}^{-1}$ LPE and (3) $0.90 \mathrm{mg} \cdot \mathrm{L}^{-1} \mathrm{LPE}$. The longkong fruits (660 fruits) were divided into three groups $(1,2$, and 3$)$, and the coating was formed by immersing the fruit in the emulsion for $1 \mathrm{~min}$ per fruit. The treated samples were dried at room temperature $\left(25^{\circ} \mathrm{C}, 60-70 \% \mathrm{RH}\right)$ for $1 \mathrm{~h}$ and then immediately transferred to refrigerated storage at $13^{\circ} \mathrm{C}$ with $90-95 \%$ relative humidity for nine days.

\section{Scanning electron microscopy (SEM)}

One drop of the reaction suspension was spread on a microfilter membrane and vacuum-dried at room temperature. The sample was placed on a stub, coated with a gold layer, and then observed under an SEM (SU-5000; Hitachi High-Technologies Corporation, Tokyo, Japan).

\section{Decay incidence}

The postharvest decay of fruits was determined as a percentage. The incidence of decay was calculated for decayed fruits from 120 fruits in total in each treatment. Whole-fruit decay originating from quiescent infections was subjectively evaluated by the modified method of Fallik et al. (1993).

\section{Weight loss}

Longkong fruit from each treatment were individually weighed. The percentage of fruit weight loss during storage was calculated using the following equation:

Total weight loss (\%)

$=[$ (initial weight of fruit - final weight of fruit $) /$ (initial weight of fruit) $] \times 100$.

\section{Determination of fruit browning}

Peel (pericarp) browning was estimated as a browning score by measuring the extent of the total browning area on each fruit surface based on the following scores: $1=$ no browning, $2=<20 \%$ of the peel surface, $3=20-40 \%$ of the peel surface, and $4=40-60 \%$ of the peel surface and $5 \geq 60 \%$ of the peel surface. The nonmarketability of longkong fruit was indicated by a peel browning score $\geq 4$.

\section{Total phenolic content}

The total phenolic content was quantified using the method proposed by Singleton et al. (1999). Extractions were prepared from the centre of the longkong peel. Two grams of longkong peel were homogenized with $20 \mathrm{~mL}$ of $80 \%$ ethanol for $1 \mathrm{~min}$. The extract was filtered and centrifuged at $10,000 \mathrm{rpm}$ for $15 \mathrm{~min}$. The supernatant $(1 \mathrm{~mL})$ was mixed with $1 \mathrm{~mL}$ of FolinCiocalteu reagent (Sigma Aldrich, Buchs, Switzerland) and $10 \mathrm{~mL}$ of $7 \%$ sodium carbonate. The final volume was adjusted to $25 \mathrm{~mL}$ by $\mathrm{DW}$, and the sample was incubated at the room temperature for $1 \mathrm{~h}$. The absorbance was read at $760 \mathrm{~nm}$ by using a spectrophotometer (UV-1601; Shimadzu Corporation, Kyoto, Japan), and the units were expressed as milligrams of gallic acid equivalents per gram fresh weight of longkong peel.

\section{Extraction and assays of PPO and POD activities}

The pericarp tissues $(2 \mathrm{~g})$ from 20 fruits were homogenized in $20 \mathrm{~mL}$ of $0.05 \mathrm{M}$ phosphate buffer $(\mathrm{pH} 7)$ and $0.2 \mathrm{~g}$ of polyvinyl pyrrolidone (insoluble) at $4^{\circ} \mathrm{C}$. The extract was collected by filtration through cheesecloth and then centrifuged for $20 \mathrm{~min}$ at $12,500 \mathrm{rpm}$ at $4^{\circ} \mathrm{C}$. The supernatant was collected as the crude enzyme extract.

PPO activity was assayed by measuring the substrate oxidation of 4-methylcatechol at $410 \mathrm{~nm}$ using a spectrophotometer (UV-1601; Shimadzu Corporation) according to the method of Jiang (2000). One unit of PPO activity was defined as a change of 0.001 in the absorbance per minute.

POD activity was assayed according to the method of Zhang et al. (2005). The 3-mL reaction mixture included $20 \mu \mathrm{L}$ of enzyme extract, $2.78 \mathrm{~mL}$ of $0.05 \mathrm{M}$ phosphate buffer $(\mathrm{pH} 7.0), 0.1 \mathrm{~mL}$ of $20 \mathrm{mM} \mathrm{H}_{2} \mathrm{O}_{2}$ and $0.1 \mathrm{~mL}$ of $20 \mathrm{mM}$ guaiacol. An increase in absorbance at $470 \mathrm{~nm}$ was recorded for $2 \mathrm{~min}$. One unit of enzyme activity was defined as the amount of enzyme that caused a change of 0.01 in the absorbance per minute.

The protein contents were determined from crude enzyme extracts by using the Bradford method (Bradford, 1976) with bovine serum albumin as a standard.

\section{Total titratable acidity}

Total titratable acidity (TA) was measured as follows: $1 \mathrm{~mL}$ of extracted juice was diluted with $9 \mathrm{~mL}$ of DW, and $0.1 \mathrm{M} \mathrm{NaOH}$ was added by using an automatic titrator to a final $\mathrm{pH}$ of 8.1 was reached (AUT-501; DKK-TOA Corporation, Tokyo, Japan). Total titratable acidity was expressed as a percentage of citric acid. All of the measurements were carried out according to AOAC procedures (Horwitz, 2000; Nunes et al., 2009).

\section{Total soluble solid content}

Total soluble solids (TSSs) from fruit juice (the aril part) were measured by using a digital refractometer (PAL-1; ATAGO CO., LTD., Tokyo, Japan). The TSS results were expressed as percentages. 
Statistical analysis

All of the experiments were performed using a completely randomized design. Three replications were carried out to examine the analytical parameters of decay incidence, browning assessment, weight loss, titratable acidity and soluble solid contents. To determine the total phenol compounds and activities of PPO and POD, three replicates were used. The treatment means were separated using the least significant difference method. The significance level was set as $P<0.05$. The data are presented as the means \pm standard error (SE).

\section{Results and Discussion}

Figure 1 shows that LPE-silver particles formed in the suspension (A: $0 \mathrm{mg}$ of LPE, B: $1 \mathrm{mg}$ of LPE; and C, D: $2 \mathrm{mg}$ of LPE). These micrographs demonstrated the presence of fine particles of silver with a mean size ranging from 71-254 nm (Fig. 1A). In Figure 1B, it was revealed that at $1 \mathrm{mg}$ of LPE, the silver solution cyclically formed silver particles with an average particle size of approximately $448-625 \mathrm{~nm}$. Similarly, Babu and Prabu (2011) synthesized 150- to 1000-nm silver particles using a flower extract of Calotropisprocera. Figure 1D shows silver $(130 \mathrm{~nm})$ in the centre of LPE and distributed in solution. The particles were approximately $1.58 \mu \mathrm{m}$ in size. The silver ions could be changed to particles using the peel extract of longkong (Aglaia dookkoo Griff.).

Longkong fruit coated with $0.90 \mathrm{mg} \cdot \mathrm{L}^{-1} \mathrm{LPE}$ in silver particle-alginate displayed different effects in terms of the reduction in decay incidence (Fig. 2A). At day 6, control fruits showed a $13 \%$ decay incidence, while fruits treated with 0.45 and $0.90 \mathrm{mg} \cdot \mathrm{L}^{-1} \mathrm{LPE}$ showed decay incidences of approximately $6 \%$ and $0 \%$, respectively. Following storage, all longkong fruits coated with 0.45 and $0.90 \mathrm{mg} \cdot \mathrm{L}^{-1}$ of LPE showed a lower decay incidence $(0-10 \%)$ than $20 \%$ of control fruits coated without LPE. Farunsang et al. (2017) indicated that Colletotrichum spp. and Lasiodiplodia sp. were significant pathogens that caused the postharvest fruit rot of longkong. The peel of longkong fruit exhibited higher $\mathrm{O}_{2}$-bullet and $\mathrm{OH}$-bullet scavenging activities. Phytochemical analysis of longkong peel showed the presence of various phenolic substances, mainly scopoletin, rutin, and chlorogenic acid. As reported previously, phenolic compounds from mango peel extract, such as trans-cinnamic acid, inhibit the mycelial growth of Colletotrichum falcatum and Phytophthora capsici (Kim et al., 2012). Nychas et al. (2003) reported the effect of bioactive plant compounds on inhibiting the growth of bacterial cells on minimally processed foods, such as degradation of the cell wall, damage to cytoplasmic membrane proteins of Staphylococcus aureus and Pseudomonas aeruginosa (Lambert et al., 2001), and leakage and coagulation of the cytoplasmic contents of Candida spp. (Burt, 2004). In fact, silver particles can attach to cell membranes and penetrate

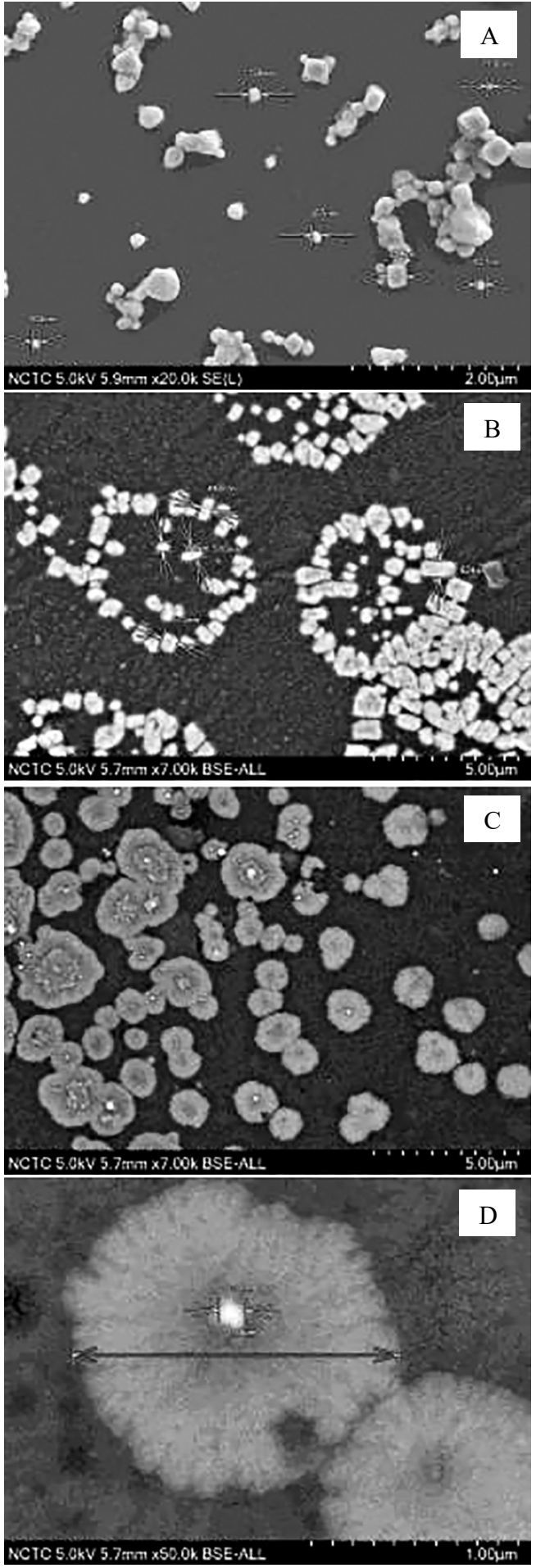

Fig. 1. Scanning electron micrographs of silver particles synthesized with LPE powder at $0 \mathrm{mg}$ (A), $1 \mathrm{mg}$ (B), and $2 \mathrm{mg}$ (C and D). Silver nitrate $(1.0 \mathrm{mM})$ was incubated at $80^{\circ} \mathrm{C}$ for $3 \mathrm{~min}$ at pH 3.0 (magnification, 19,000×).

bacteria, while silver ions can disrupt major biological processes, leading to cell death. The particles release silver ions $\left(\mathrm{Ag}^{2+}\right)$ within bacterial cells, enhancing the bactericidal activity of the silver particles (Feng et al., 2000; Rai et al., 2009). Meanwhile, alginate could re- 

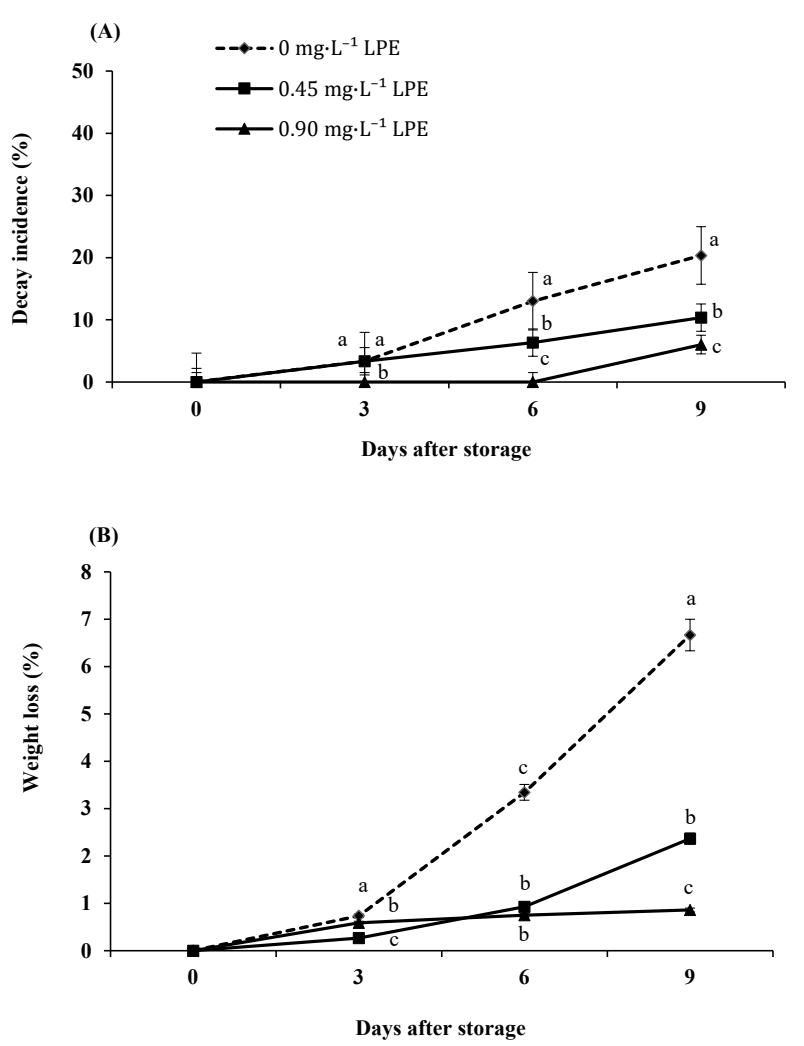

Fig. 2. Decay incidence (A) and weight loss (B) of coated longkong treated with solutions of 0 (control), 0.45 and $0.90 \mathrm{mg} \cdot \mathrm{L}^{-1} \mathrm{LPE}$ during storage for nine days at $13^{\circ} \mathrm{C}$ and 90 95\% RH. Different letters indicate significant differences among the samples after storage at different LPEs at $P<0.05$ by Duncan's multiple-range test. The values in the figure are expressed as means $\pm \mathrm{SE}$ of three replicates.

duce moisture migration, gaseous exchange, and oxidative reactions and suppress pathogen growth and physiological disorders (Gundewadi et al., 2018; Salvia-Trujillo et al., 2015; Sessa et al., 2015).

Weight loss suggests fruit dehydration caused by transpiration and involves water transfer from cells to the surrounding atmosphere; this enables the evaluation of coating efficiency for quality preservation (PérezGago et al., 2010). In this study, an alginate coating was used to form a film, acting as a gas exchange barrier that did not modify water transport. LPE was introduced into the coating to create a lipophilic environment capable of acting as a barrier against water, as demonstrated in the samples with 0.45 and $0.90 \mathrm{mg} \cdot \mathrm{L}^{-1}$ LPE. The results showed less weight loss in all of the LPE-coated fruits than in the control fruits during storage (Fig. 2B).

The browning of the longkong peel increased gradually over the nine days of storage with all treatments (Fig. 3A). The browning of the control fruits was greater than that of fruits coated with silver particlealginate containing 0.45 and $0.90 \mathrm{mg} \cdot \mathrm{L}^{-1} \mathrm{LPE}$ after nine days of storage. The phenolic content (tannic acid), as a strong cross-linker, reduced the water vapor perme- ability and caused thicker film formation (Menezes et al., 2019). Longkong coated with silver particlealginate containing LPE at 0.45 and $0.90 \mathrm{mg} \cdot \mathrm{L}^{-1}$ showed delayed longkong browning after six days of storage. This delay occurred because of increased cross linking in the presence of LPE, leading to an improvement in the coating properties. Figure 1A shows the presence of small silver particles without LPE that increased with the addition of LPE at 0.45 and $0.90 \mathrm{mg} \cdot \mathrm{L}^{-1}$ compared with the other particle groups (Fig. 1B, C, respectively). The browning score of longkong coated with silver particle-alginate plus LPE at $0.45 \mathrm{mg} \cdot \mathrm{L}^{-1}$ was 3 , which was significantly lower than that of the control on the ninth day of storage. The better result obtained with thicker coatings in the presence of LPE may be due to the coating acting as a barrier against oxygen, which is important for the progression of browning reactions.

The phenolic content in the peels of all treatments decreased during the storage period (Fig. 3B). Browning is mainly caused by the oxidation of phenolic compounds to $o$-quinones; this reaction is catalysed by oxidative enzymes, including PPO and POD (Garcia and Barrett, 2002). Assuming a reduction in phenolic compounds, treatments that inhibit the reactions in which oxidative enzymes are involved (i.e., PPO and POD) may accumulate higher levels of phenols (Capotorto et al., 2018). The initial total phenolic content of the longkong fruit coated with silver particlealginate containing $0.45 \mathrm{mg} \cdot \mathrm{L}^{-1} \mathrm{LPE}$ was significantly higher than that of control fruits and longkong fruit treated with silver particle-alginate containing $0.90 \mathrm{mg} \cdot \mathrm{L}^{-1}$ LPE. The total phenolic content of longkong was significantly increased with the continuous increase in the weeks of the maturation period from 13 weeks $(42.65 \mathrm{mg} / 100 \mathrm{~g})$ to 16 weeks $(58.71 \mathrm{mg} /$ $100 \mathrm{~g}$ ) (Venkatachalam and Meenune, 2012). Lichanporn et al. (2009) reported that the total phenolic content in all parts (lower, middle, and top) of the fruit was significantly increased during storage, while the total phenolic content of the lower part accumulated faster than that in the middle or top parts. The higher level of phenolic content in longkong fruit is also a reason for its enzymatic browning. The postharvest browning of fruits and vegetables is related to the cellular synthesis of phenolic compounds, which are oxidized into quinines and polymerized into brown polymers (Martinez and Whitaker, 1995). As a key enzyme in the early steps of phenolic biosynthesis, PAL plays an important role in the production and accumulation of phenols in fruits and vegetables (Ke and Saltveit, 1989) and is genetically induced by various stress conditions (Dixon and Paiva, 1995). As shown in Figure 3B, the initial total phenolic content of longkong fruit coated with silver particle-alginate containing $0.90 \mathrm{mg} \cdot \mathrm{L}^{-1}$ LPE was considerably lower than that in the control $(P$ $<0.05$ ); after nine days of storage, the fruits coated 

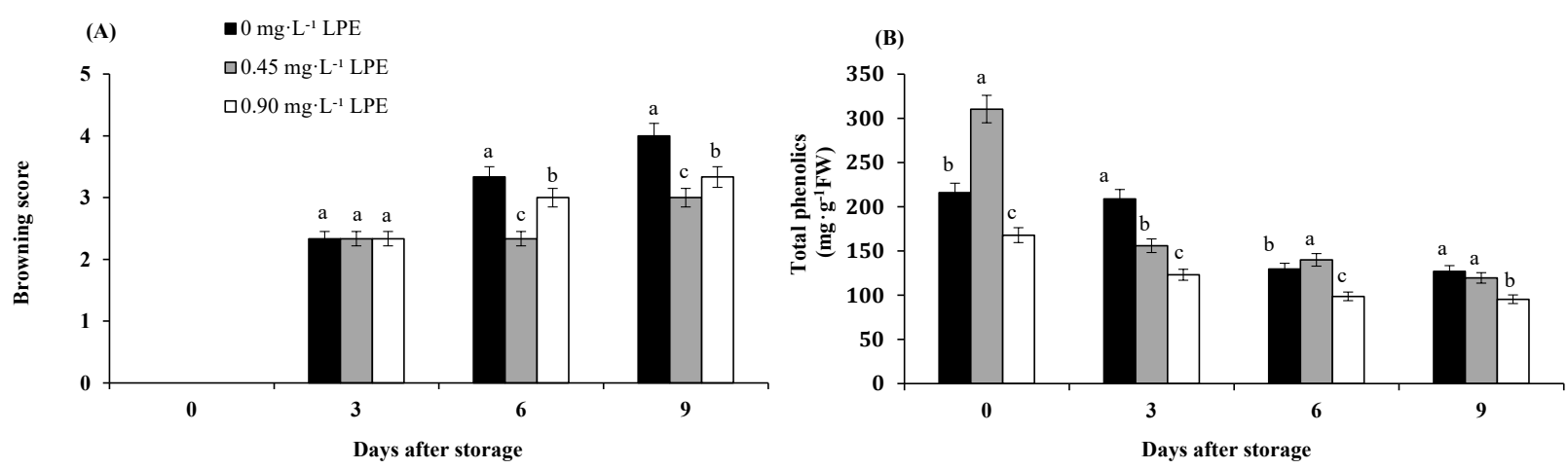

(C)
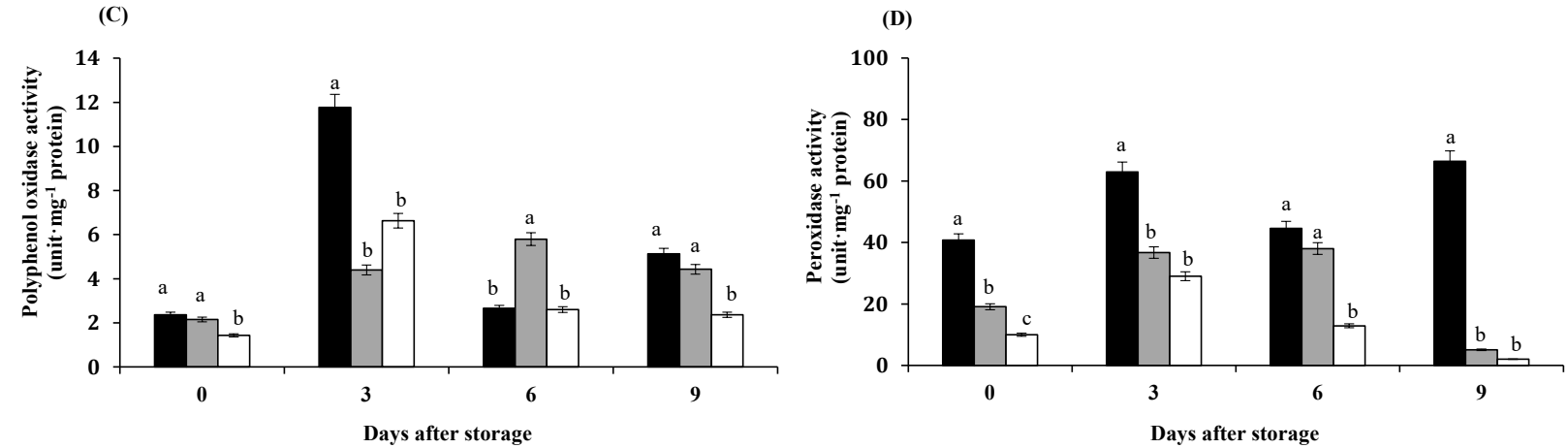

Fig. 3. Browning score (A), total phenolic compounds (B), polyphenol oxidase activity (C), and peroxidase activity (D) of coated longkong treated with solutions of 0 (control), 0.45 and $0.90 \mathrm{mg} \cdot \mathrm{L}^{-1} \mathrm{LPE}$ during storage for nine days at $13^{\circ} \mathrm{C}$ and $90-95 \% \mathrm{RH}$. The dashed line represents the non-marketability level of longkong fruit. Different letters indicate significant differences among the samples after storage at different LPE concentrations at $P<0.05$ by Duncan's multiple-range test. The values in the figure are expressed as means $\pm \mathrm{SE}$ of three replicates.

with $0.90 \mathrm{mg} \cdot \mathrm{L}^{-1}$ of LPE had the lowest total phenolic content $\left(95.35 \mathrm{mg} \cdot \mathrm{g}^{-1} \mathrm{FW}\right)$. As a potential coating material to delay the ripening process, the effect of alginate is enhanced upon the incorporation of any antioxidant or antimicrobial agent (Nair et al., 2018). Although LPE is a rich source of phenols, the inhibitory role of phenolic compounds, particularly cinnamic acid, against PPO is due to its homologue structure with endogenous phenolic substrates (Shi et al., 2005).

The PPO activity was highest in all treatments on day 3 , except for treatment with $0.45 \mathrm{mg} \cdot \mathrm{L}^{-1} \mathrm{LPE}$. The PPO activity in the treatments with 0.45 and $0.90 \mathrm{mg} \cdot \mathrm{L}^{-1}$ LPE was lower than that in the control samples (Fig. 3C). The latent form of PPO is often activated during ripening, senescence or stress conditions when the membrane permeability is dysfunctional, resulting in increased PPO activity (Mayer, 1987). Although the PPO activity in longkong fruit increased during the first three days of storage, at the end of storage the PPO activities in the treatments with 0.45 and $0.90 \mathrm{mg} \cdot \mathrm{L}^{-1} \mathrm{LPE}$ were lower than those of the control at 4.42 and 2.37 unit $\cdot \mathrm{mg}^{-1}$ protein, respectively. POD activity increased rapidly in the treatments with control fruit in the first three days, followed by a rapid decrease (Fig. 3D). Generally, enzymatic browning in fruits and vegetables is associated with a reaction between polyphenol substrates and oxygen with PPO and POD (Sapers and Hicks, 1989). Although PPO can catalyse the hydroxy- lation of monophenols to $o$-diphenols and the oxidation of $o$-diphenols to their corresponding $o$-quinones (Richard and Gauillard, 1997), diphenols may function as reducing substrates in this reaction (Chisari et al., 2007). The activity of POD, another oxidoreductase enzyme involved in enzymatic browning, in the treatments with 0.45 and $0.90 \mathrm{mg} \cdot \mathrm{L}^{-1}$ LPE increased progressively during the first three days of storage. However, the POD of fruit coated with silver particlealginate containing all concentrations of LPE was significantly lower than that of the control samples after nine days of storage. The concentration in the treatment with $0.90 \mathrm{mg} \cdot \mathrm{L}^{-1}$ LPE was the lowest at 2.05 units $\cdot \mathrm{mg}^{-1}$ protein (Fig. 3D). However, the PPO and POD activities increased rapidly in all treatments in the first three days. These results may have been caused by the increased longkong pericarp PPO, POD, and PAL enzyme activities during on-tree maturation, inducing peel redness during ripening. Furthermore, the longkong exocarp (outer peel) contains many trichomes that could be susceptible to environmental stresses, and this exocarp acts as a potent stimulator of PPO and POD activities (Venkatachalam and Meenune, 2012). However, the POD and PPO activities of fruit coated with silver particle-alginate containing 0.45 and $0.90 \mathrm{mg} \cdot \mathrm{L}^{-1} \mathrm{LPE}$ were lower than those of the control samples because LPE exogenous phenolics possess antioxidant activity by capturing free radicals produced 
during oxidative stress (Peretto et al., 2017). Moreover, LPE can promote auto-oxidation and metal chelation and modulated the activity of some enzymes (Howard et al., 2003).

Figure 3A-D show the effect of LPE on the browning score, phenolic content, and PPO and POD activities. All of the treatments with no browning at zero time correlated better with the PPO activity. The control sample showed increased PPO activity on day 3, and the phenolic content was reduced, indicating that enzymatic browning of fruit is the key property of phenolic oxidation by PPO (Jiang et al., 2004). Additionally, peroxidase reacts with phenolic compounds using $\mathrm{H}_{2} \mathrm{O}_{2}$ as a co-substrate (Nicolas et al., 1994), and the POD activity of control fruit showed high activity during storage. The increase in POD activity was involved in stress conditions such as membrane damage (Fig. 3A), weight loss (Fig. 2A) and disease (Fig. 2B). The longkong fruit coating with silver particle-alginate containing $0.45 \mathrm{mg} \cdot \mathrm{L}^{-1}$ LPE showed increased PPO and POD activities on the 3rd and 6th days and then decreased PPO and POD activities until the end of storage that were related to the browning score, but these were lower than those of control fruit. These differences may be due to the fact that the coating acted as a semi-permeable barrier against oxygen, water loss and oxidation reaction rates (Arowora et al., 2013), and fruit coated with silver particle-alginate containing LPE promoted restricted gas exchange on the surface of longkong.

The total titratable acidity of all fruits increased within six days and then decreased slowly until day 9 (Fig. 4A). The coating treatment with $0.90 \mathrm{mg} \cdot \mathrm{L}^{-1} \mathrm{LPE}$ showed lower titratable acidity than any other treatments after three days of storage. The decrease in acidity after six days of storage may have been due to the rapid utilization of acids in respiratory pathways following maturity, demonstrating that the decrease depends on many factors, including the LPE concentration on the coating's surface (Jain et al., 2003; MercadoSilva et al., 1998; Singh and Pal, 2008). The total soluble solid content of chemically-treated fruits changed slightly during the nine days of storage (Fig. 4B). Application of an alginate coating was the most effective to stop the conversion of acids present in the fruit into sugars (Bassetto et al., 2005) because they created a new environment on the surface of longkong fruit.

In conclusion, longkong fruit coated with a silver particle-alginate containing 0.45 and $0.90 \mathrm{mg} \cdot \mathrm{L}^{-1} \mathrm{LPE}$ demonstrated delayed browning and decreased weight loss, decay incidence and POD and PPO activities during storage. Additionally, longkong fruit coated with silver particle-alginate containing 0.45 and $0.90 \mathrm{mg} \cdot \mathrm{L}^{-1}$ LPE showed a higher total phenolic content than the control fruits. The fruits coated with silver particlealginate alone, and those containing $0.45 \mathrm{mg} \cdot \mathrm{L}^{-1} \mathrm{LPE}$, showed no differences in titratable acidity on the 3rd and 6th days of storage, while longkong fruit treated
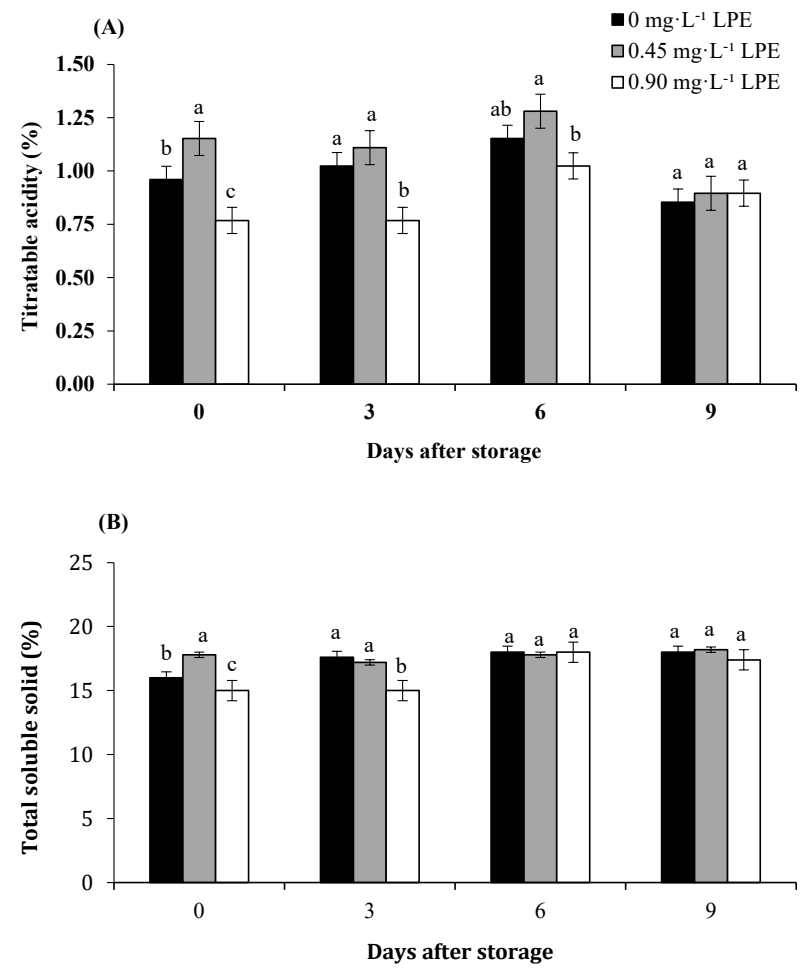

Fig. 4. Titratable acidity (A) and total soluble solid (B) of coated longkong treated with solutions of 0 (control), 0.45 and $0.90 \mathrm{mg} \cdot \mathrm{L}^{-1} \mathrm{LPE}$ during storage for nine days at $13^{\circ} \mathrm{C}$ and 90 95\% RH. Different letters indicate significant differences among the samples after storage at different LPE concentrations at $P<0.05$ by Duncan's multiple-range test. The values in the figure are expressed as the means $\pm \mathrm{SE}$ of three replicates.

with $0.90 \mathrm{mg} \cdot \mathrm{L}^{-1} \mathrm{LPE}$ had a lower titratable acidity than any other treatments after three days of storage. The total soluble solid content of longkong fruit for all of the treatments changed slightly during the nine days of storage. Further research is warranted to determine the functional significance of key sugar accumulationrelated genes using specific primers based on the genome sequences of longkong.

\section{Literature Cited}

Arowora, K. A., J. O. Williams, C. O. Adetunji, O. B. Fawole, S. S. Afolayan, O. O. Olaleye, J. B. Adetunji and B. A. Ogundele. 2013. Effect of aloe vera coating on quality characteristics of oranges stored under cold storage. Greener J. Agric. Sci. 3: 39-47.

Babu, S. A. and H. G. Prabu. 2011. Synthesis of AgNPs using the extract of Calotropisprocera flower at room temperature. Mater. Lett. 65: 1675-1677.

Baldwin, E. A. 2007. Surface treatments and edible coatings. p. 477-508. In: M. S. Rahman (ed.). Handbook of Food Preservation, $2^{\text {nd }}$ edition, CRC Press, FL.

Bassetto, E., A. P. Jacomino, A. L. Pinheiro and R. A. Kluge. 2005. Delay of ripening of 'Pedro Sato' guava with 1methylcyclopropene. Postharvest Biol. Technol. 35: 303308.

Bradford, M. M. 1976. A rapid and sensitive method for the quantitation of microgram quantities of protein utilizing the principle of protein-dye binding. Anal. Biochem. 72: 248- 
254.

Burt, S. 2004. Essential oils: their antibacterial properties and potential applications in foods: A review. Int. J. Food Microbiol. 94: 223-253.

Cao, Z., H. Fu, L. Kang, L. Huang, T. Zhai, Y. Ma and J. Yao. 2008. Rapid room-temperature synthesis of silvernanoplates with tunable in-plane surface plasmon resonance from visible to near-IR. J. Mater. Chem. 18: 2673-2678.

Capotorto, I., M. L. Amodio, M. T. B. Diaz, M. L. V. Chiara and G. Colelli. 2018. Effect of anti-browning solutions on quality of fresh-cut fennel during storage. Postharvest Biol. Technol. 137: 21-30.

Chang, T. S. 2009. An updated review of tyrosinase inhibitors. Int. J. Mol. Sci. 10: 2440-2475.

Chen, C., X. Peng, R. Zeng, M. Chen, C. Wan and J. Chen. 2016. Ficushirta fruits extract incorporated into an alginate-based edible coating for Nanfeng mandarin preservation. SciHortic. 202: 41-48.

Chisari, M., R. N. Barbagallo and G. Spagna. 2007. Characterization of polyphenol oxidase and peroxidase and influence on browning of cold stored strawberry fruit. J. Agric. Food Chem. 55: 3469-3476.

Choi, O., K. K. Deng, N. J. Kim, L. Ross Jr., R. Y. Surampalli and Z. Hu. 2008. The inhibitory effects of silver nanoparticles, silver ions, and silver chloride colloids on microbial growth. Water Resour. Res. 42: 3066-3074.

Coma, V. 2008. Bioactive packaging technologies for extended shelf life of meat-based products. Meat Sci. 78: 90-103.

Constabel, C. P. and R. Barbehenn. 2008. Defensive roles of polyphenol oxidase in plants. p. 253-269. In: A. Schaller (ed.). Induced Plant Resistance to Herbivory. Springer Verlag, Berlin.

Cutter, C. N. and S. S. Summer. 2002. Application of edible coatings on muscle foods. p. 467-484. In: A. Gennadios (ed.). Protein-Based Films and Coatings, CRC Press, FL.

Dixon, R. A. and N. L. Paiva. 1995. Stress induced phenylpropanoid metabolism. Plant Cell 7: 1085-1097.

Fallik, E., J. Klein, S. Grinberg, E. Lomaniec, S. Lurie and A. Lalazar. 1993. Effect of postharvest heat treatment of tomatoes on fruit ripening and decay caused B. botrytis cinerea. Plant Dis. 77: 985-988.

Farunsang, N., U. Farungsang and Y. Munon. 2017. Fungi involved in competitive disease on postharvest longkong. Agricultural Sci. J. 48(3) (Suppl.): 137-140.

Feng, Q. L., J. Wu, G. Q. Chen, F. Z. Cui, T. N. Kim and J. O. Kim. 2000. A mechanistic study of the antibacterial effect of silver ions on Escherichia coli and Staphylococcus aureus. J. Biomed. Mater. Res. 52: 662-668.

Garcia, E. and D. M. Barrett. 2002. Preservative treatments for fresh-cut fruits and vegetables. p. 267-303. In: O. Lamikanra (ed.). Fresh-Cut Fruits and Vegetables. Science, Technology, and Market. CRC Press, FL.

Gundewadi, G., S. G. Rudra, D. J. Sarkar and D. Singh. 2018. Nanoemulsion based alginate organic coating for shelf life extension of okra. Food Packaging Shelf. 18: 1-12.

Horwitz, W. 2000. AOAC Official Method 967.21: Ascorbic acid in vitamins preparations and juices, 2,6-dichloroindophenol titrimetric method. p. 16. 17th edition. AOAC international Rockville.

Howard, M. B., N. A. Ekborg, R. M. Weiner and S. W. Hutcheson. 2003. Detection and characterization of chitinases and other chitin-modifying enzymes. J. Ind. Microbiol. Biotechnol. 30: 627-635.

Jain, N., K. Dhawan, S. Malhotra and R. Singh. 2003. Biochemistry of fruit ripening of guava (Psidium guajava L.): Com- positional and enzymatic changes. Plant Foods Hum. Nutr. 58: 309-315.

Jiang, Y. M. 2000. Role of anthocyanins, polyphenol oxidase and phenols in lychee pericarp browning. J. Sci. Food Agric. 80: 305-310.

Jiang, Y., X. Duan, D. Joyce, Z. Zang and J. Li. 2004. Advance in understanding of enzymatic browning in harvested litchi fruit. Food Chem. 88: 443-446.

Ke, D. and M. E. Saltveit. 1989. Wound-induced ethylene production, phenolic metabolism and susceptibility to russet spotting in iceberg lettuce. Plant Physiol. 76: 412-418.

Kim, H., H. Kim, A. Mosaddik, R. Gyawali, K. S. Ahn and S. K. Cho. 2012. Induction of apoptosis by ethanolic extract of mango peel and comparative analysis of the chemical constitutes of mango peel and flesh. Food Chem. 133: 416-422.

Klungsupya, P., N. Suthepakul, T. Muangman, U. Rerk-Am and J. Thongdon-A. 2015. Determination of free radical scavenging, antioxidative DNA damage activities and phytochemical components of active fractions from Lansium domesticum Corr. fruit. Nutrients 7: 6852-6873.

Kumar, B., K. Smita, L. Cumbal and Y. Angulo. 2015. Fabrication of silver nanoplates using Nephelium lappaceum (Rambutan) peel: A sustainable approach. J. Mol. Liq. 211: 476-480.

Lambert, R. J. W., P. N. Skandamis, P. Coote and G. J. E. Nychas. 2001. A study of the minimum inhibitory concentration and mode of action of oregano essential oil, thymol and carvacrol. J. Appl. Microbiol. 91: 453-462.

Liau, S. Y., D. C. Read, W. J. Pugh, J. R. Furr and A. D. Russell. 1997. Interaction of silver nitrate with readily identifiable groups: relationship to the antibacterial action of silver ions. Lett. Appl. Microbiol. 25: 279-283.

Lichanporn, I., V. Srilaong, C. Wongs-Aree and S. Kanlayanarat. 2009. Postharvest physiology and browning of longkong (Aglaia dookkoo Griff.) fruit under ambient conditions. Postharvest Biol. Technol. 52: 294-299.

Lim, T. K. 2013. Edible medicinal and non-medicinal plants. Fruits 6: 62-71.

Martinez, M. V. and J. R. Whitaker. 1995. The biochemistry and control of enzymatic browning. Trends in Food Sci. Technol. 6: $195-200$.

Mayer, A. M. 1987. Polyphenoloxidase in plants-recent progress. Phytochem. 26: 1-20.

Menezes, M. L. L. R., N. R. Pires, P. L. R. Cunha, M. F. Rosa, B. W. S. Souza, J. P. A. Feitosa and M. S. M. Souza Filho. 2019. Effect of tannic acid as crosslinking agent on fish skin gelatin-silver nanocomposite film. Food Packaging Shelf. 19: 7-15.

Mercado-Silva, E., P. Benito-Bautista, M. A. García-Velasco. 1998. Fruit development, harvest index and ripening changes of guavas produced in central Mexico. Postharvest Biol. Technol. 13: 143-150.

Meyers, M. A., A. Mishra and D. J. Benson. 2006. Mechanical properties of nanocrystalline materials. Prog. Mater. Sci. 51: 427-556.

Montero-Calderón, M., M. A. Rojas-Graü and O. Martín-Belloso. 2008. Effect of packaging conditions on quality and shelflife of fresh-cut pineapple (Ananas comosus). Postharvest Biol. Technol. 50: 182-189.

Nair, L. S. and C. T. Laurencin. 2007. Silver nanoparticles: synthesis and therapeutic applications. J. Biomed. Nanotechnol. 3: 301-316.

Nair, M. S., A. Saxena and C. Kaur. 2018. Effect of chitosan and alginate based coatings enriched with pomegranate peel extract to extend the postharvest quality of guava (Psidium 
guajava L.). Food Chem. 240: 245-252.

Nicolas, J. J., F. C. Richard-Forget, P. M. Goupy, M. Amiot and S. Aubert. 1994. Enzymatic browning reactions in apple and apple products. Crit. Rev. Food Sci. Nutr. 34: 109-157.

Nunes, C., A. E. Rato, A. S. Barros, J. A. Saraiva and M. A. Coimbra. 2009. Search for suitable maturation parameters to define the harvest maturity of plums (Prunus domestica L.): A case study of candied plums. Food Chem. 112: 570-574.

Nychas, G. J. E., C. C. Tassou and P. Skandamis. 2003. Antimicrobials from herbs and spices. p. 176-200. In: S. Roller (ed.). Natural Antimicrobials for the Minimal processing of Foods. Woodhead Publishing, Cambridge.

Peretto, G., W. X. Du, R. J. Avena-bustillos, J. D. J. Berrios, P. Sambo and T. H. McHugh. 2017. Electrostatic and conventional spraying of alginate-based edible coating with natural antimicrobials for preserving fresh strawberry quality. Food and Bioprocess Tech. 10: 165-174.

Pérez-Gago, M. B., G. A. González-Aguilar and G. I. Olivas. 2010. Edible coatings for fruits and vegetables. Stewart Postharvest Review 6: 1-14.

Queiroz, C., M. L. M. Lopes, E. Fialho and V. L. ValenteMesquita. 2008. Polyphenol oxidase: Characteristics and mechanisms of browning control. Food Rev. Int. 24: 361375.

Rai, M., A. Yadav and A. Gade. 2009. Silver nanoparticles as a new generation of antimicrobials. Biotechnol. Adv. 27: 7683.

Richard, F. F. and F. A. Gauillard. 1997. Oxidation of chlorogenic acid, catechins, and 4-methylcatechol in model solutions by combinations of pear (Pyrus communis cv Williams) peroxidase in enzymatic browning. J. Agric. Food Chem. 45: 2472-2476.

Rojas-Graü, M. A., R. Avena-Bustillos, M. Friedman, P. Henika, O. Martín-Belloso and T. McHugh. 2006. Mechanical, barrier and antimicrobial properties of apple puree edible films containing plant essential oils. J. Agric. Food Chem. 54: 9262-9267.

Rojas-Graü, M. A., R. Soliva-Fortuny and O. Martín-Belloso. 2009. Edible coatings to incorporate active ingredients to freshcut fruits: a review. Trends Food Sci. Technol. 20: 438447.

Rojas-Graü, M. A., M. S. Tapia and O. Martín-Belloso. 2008. Using polysaccharide-based edible coatings to maintain quality of fresh-cut Fuji apples. LWT-Food Sci. Technol. 41: 139-147.

Rojas-Graü, M. A., M. S. Tapia, F. J. Rodrıguez, A. J. Carmona and O. Martín-Belloso. 2007. Alginate and gellan based edible coatings as support of antibrowning agents applied on fresh-cut Fuji apple. Food Hydrocoll. 21: 118-127.

Salvia-Trujillo, L., M. A. Rojas-Graü, R. Soliva-Fortuny and O. Martín-Belloso. 2015. Use of antimicrobial nanoemulsions as edible coatings: Impact on safety and quality attributes of fresh-cut Fuji apples. Postharvest Biol. Technol. 105: 8-16.

Sapers, G. M. and K. B. Hicks. 1989. Inhibition of enzymatic browning in fruits and vegetables. p. 29-43. In: J. J. Jen (ed.). Quality Factors of Fruits and Vegetables: Chemistry and Technology. ACC Symp., Series 405. Am. Chem. Soc. Washington. DC.

Sessa, M., G. Ferrari and F. Donsi. 2015. Novel edible coating containing essential oil nanoemulsions to prolong the shelf life of vegetable products. Chem. Eng. J. 43: 55-60.

Sharma, V. K., R. A. Yngard and Y. Lin. 2009. Silver nanoparticles: green synthesis and their antimicrobial activities. Adv. Colloid Interface Sci. 45: 83-96.

Shi, Y., Q. Z. Chen, Q. Wang, K. K. Song and L. Qiu. 2005. Inhibitory effects of cinnamic acid and its derivatives on the diphenolase activity of mushroom (Agaricus bisporus) tyrosinase. Food Chem. 92: 707-712.

Singh, S. P. and R. K. Pal. 2008. Response of climacteric-type guava (Psidium guajava L.). Postharvest Biol. Technol. 47: 307-314.

Singleton, V. L., R. Orthofer and R. M. Lamuela-Raventos. 1999. Analysis of total phenols and other oxidation substrates and antioxidants by means of Folin-Ciocalteu Reagent. Methods Enzymol. 299: 152-178.

Suanphairoch, S., M. Lim, S. Sadoodee, C. Tong, S. Chanawerawan, M. Sirinupong, T. Kananurak and B. Krisornpornsan. 2003. Development on production and management of longkong in the southern region. The National Research Council of Thailand. Bangkok.

Ustunol, Z. 2009. Edible films and coating for meat and poultry. p. 245-269. In: M. E. Embuscado and K. C. Huber (eds.) Edible Films and Coatings for Food Applications, Springer, New York.

Valero, D., H. M. Díaz-Mula, P. J. Zapata, F. Guillén, D. Martínez-Romero, S. Castíllo and M. Serrano. 2013. Effects of alginate edible coating on preserving fruit quality in four plum cultivars during postharvest storage. Postharvest Biol. Technol. 77: 1-6.

Venkatachalam, K. 2016. Postharvest physiology and handling of longkong fruit: A review. Fruit 70: 69-75.

Venkatachalam, K. and M. Meenune. 2012. Changes in physiochemical quality and browning related enzyme activity of longkong fruit during four different weeks of on-tree maturation. Food Chem. 131: 1437-1442.

Zhang, Y., H. Peng, W. Huang, Y. Zhou and D. Yan. 2008. Facile preparation and characterization of highly antimicrobial colloid $\mathrm{Ag}$ or $\mathrm{Au}$ nanoparticles. J. Colloid Interface Sci. 325: 371-376.

Zhang, Z., X. Pang, D. Xuewu, Z. Ji and Y. Jiang. 2005. Role of peroxidase in anthocyanin degradation in litchi fruit pericarp. Food Chem. 90: 47-52. 